\title{
Comparative study on the fatigue behaviour of SCC and VC
}

\author{
Sara Korte ${ }^{1,2, a}$, Veerle Boel ${ }^{1,2, b}$, Wouter De Corte ${ }^{1,2, c}$, Geert De Schutter $^{2, d}$ \\ ${ }^{1}$ Department of Industrial Technology and Construction, Faculty of Engineering and Architecture, \\ Ghent University, Valentin Vaerwyckweg 1, B-9000 Ghent, Belgium
}

${ }^{2}$ Magnel Laboratory for Concrete Research, Department of Structural Engineering, Faculty of Engineering and Architecture, Ghent University, Technologiepark 904, B-9052, Ghent, Belgium

\author{
a'Sara.Korte@UGent.be, 'Veerle.Boel@UGent.be, Wouter.DeCorte@UGent.be, \\ 'Geert.DeSchutter@UGent.be
}

\begin{abstract}
Keywords: Vibrated Concrete, Self-Compacting Concrete, Cyclic Loading, Fatigue, S-N Curve, Crack Growth, Four-Point Bending Test
\end{abstract}

\begin{abstract}
Continuous cyclic loading on concrete constructions involves a progressive cracking mechanism, leading to significant changes of the material properties during the lifetime of the structure. Gradually, irreversible damage is inflicted and the carrying capacity is affected, which may cause structural collapse at a stress or strain level much lower than in case of a single static load. This so-called fatigue phenomenon is well-documented in literature for traditional, vibrated concrete (VC), but this is not the case for self-compacting concrete (SCC). Given the fact that this latter concrete type is already used worldwide in many types of structures, including cyclically loaded ones, a good knowledge and understanding of the static and fatigue material behaviour is crucial. Up till now, it is unsure whether SCC performs better, worse, or equally under fatigue loading conditions. Therefore, in this study, destructive four-point bending tests are performed on large beams, made from VC and SCC, both statically and cyclically (at different loading rates). A comparison of the deflection, strain, crack pattern and crack width evolution of the different concrete types is made. The results reveal some significant differences regarding concrete strain and crack width development during the cyclic tests.
\end{abstract}

\section{Introduction}

The substantially different composition of self-compacting concrete (SCC), compared to vibrated concrete (VC), affects various material characteristics. For instance, the higher content of fine particles (e.g. by adding fillers) influences the whole microstructure, making the interfacial transition zone of SCC denser and consequently increasing the compressive and tensile strength, opposed to VC with similar w/c ratio [1]. Furthermore, the reduction of coarse aggregates in SCC contributes to a lower stiffness, when comparing to $\mathrm{VC}$ of equal strength [1,2]. Additionally, it has been proven that both concrete types demonstrate a different fracture behaviour $[2,3]$.

Based on these observations, the fatigue resistance of both concrete types might be different, as well, since it is governed by a damage process, related to micro-crack initiation, material damage, and fracture behaviour in general. As stated in [4,5], cracking of concrete is determined by the strength of the cement paste, and also by the location and size of the aggregates. Moreover, previous research proves that SCC with equal compressive strength, compared to VC, performs worse in cyclic three-point bending and wedge-splitting tests [6].

\section{Experimental program}

Mixtures. Two concrete batches (VC and SCC) with the same cement type and identical aggregate types and sizes were used for the four-point bending test beams. Moreover, there was aimed for a similar compressive strength. Table 1 and Table 2 provide the composition quantities of both mixtures, and their main properties, determined on several control specimens according to the prevailing standards. 
Table 1 - Concrete compositions

\begin{tabular}{lcc}
\hline Composition & VC $\left[\mathbf{k g} / \mathbf{m}^{3}\right]$ & $\mathbf{S C C}\left[\mathbf{k g} / \mathbf{m}^{3}\right]$ \\
\hline CEM III/A 42.5 LA & 365 & 365 \\
Water & 175 & 194 \\
Sand 0/4 & 726 & 808 \\
Crushed limestone 2/6.3 & 652 & 451 \\
Crushed limestone 6.3/14 & 434 & 265 \\
Limestone filler & - & 235 \\
Superplasticizer & 2.9 & 8.0 \\
\hline
\end{tabular}

Table 2 - Concrete hardened properties

\begin{tabular}{lcc}
\hline Properties & VC [MPa] & SCC [MPa] \\
\hline $\mathrm{f}_{\mathrm{cm}}$ & $49.8 \pm 5.0$ & $43.8 \pm 1.2$ \\
$\mathrm{f}_{\mathrm{c}, \mathrm{cub}, \mathrm{m}}$ & $57.7 \pm 1.4$ & $54.5 \pm 5.0$ \\
$\mathrm{f}_{\mathrm{ck}}=\mathrm{f}_{\mathrm{cm}}-1.64 \mathrm{~s}^{*}$ & 41.5 & 41.8 \\
$\mathrm{f}_{\mathrm{c}, \mathrm{cub}, \mathrm{k}}=\mathrm{f}_{\mathrm{cccub}, \mathrm{m}}-1.64 \mathrm{~s}^{*}$ & 55.4 & 46.3 \\
$\mathrm{f}_{\mathrm{ctm}}=0.3 \mathrm{f}_{\mathrm{ck}} / 2$ & 3.6 & 3.6 \\
$\mathrm{E}_{\mathrm{cm}}$ & 38,210 & 33,082 \\
\hline$*_{S}=$ standard deviation & &
\end{tabular}

Specimens. In order to achieve concrete crushing at ultimate load with the steel rebar deformation remaining fully elastic, the $2.40 \mathrm{~m}$ long beams are over-reinforced by using three longitudinal bars $\varnothing 20 \mathrm{~mm}$ at the bottom, two longitudinal bars $\varnothing 6 \mathrm{~mm}$ at the top, and vertical stirrups $\varnothing 6 \mathrm{~mm}$ every $55 \mathrm{~mm}$ (Fig. 1). In addition, the upper part of the geometrical section is narrowed, thus generating larger concrete bending stresses than there would occur in case of a rectangular section.

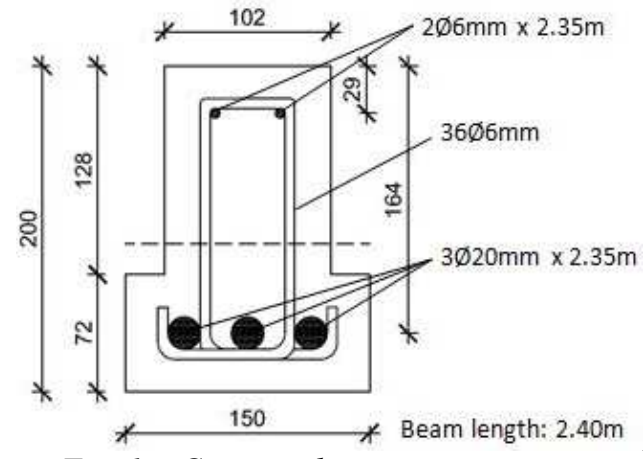

Fig. 1 - Concrete beam cross section

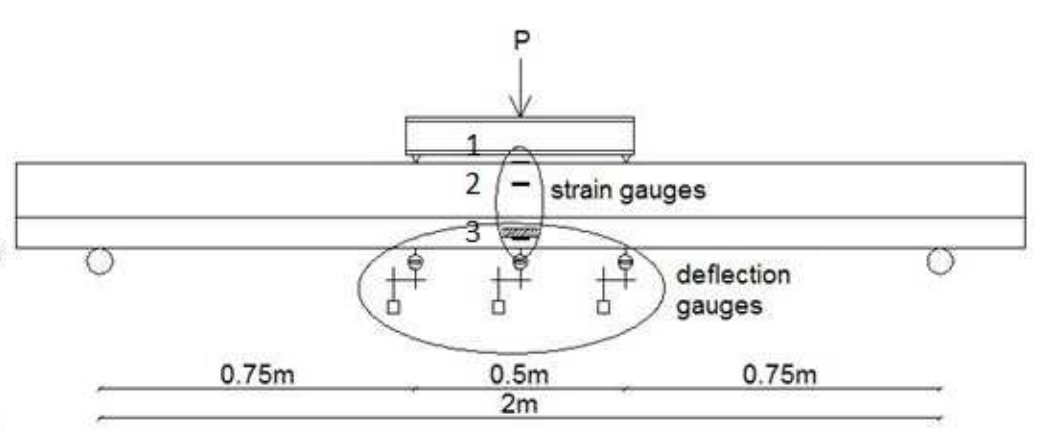

Fig. 2 - Test setup

Test procedure. Fig. 2 depicts the four-point bending test setup, applied for both static and fatigue tests. During all the experiments, the structural behaviour of the beams was registered by means of three strain gauges $\left(\mathrm{N}^{\circ} 1\right.$ in the middle of the top surface, $\mathrm{N}^{\circ} 2$ along the side of the beam at $5 \mathrm{~cm}$ from the top, $\mathrm{N}^{\circ} 3$ at the lower side of the middle rebar) and three deflection gauges (at midspan and below the point loads). The crack width evolution was measured using a crack width microscope with an accuracy of $20 \mu \mathrm{m}$.

Six reference beams ( $3 \mathrm{VC}$ and $3 \mathrm{SCC}$ ) were tested statically, with increments of $5 \mathrm{kN}$ up until failure, in order to determine the failure mechanism and the ultimate load $\mathrm{P}_{\text {ult. }}$ Based on this, the cyclic tests were conducted by applying a sinusoidal load function between a lower and upper limit of $25 \%$ and $65 \%$ of $\mathrm{P}_{\mathrm{ult}}, 10 \%$ and $70 \%$ of $\mathrm{P}_{\mathrm{ult}}$, or $10 \%$ and $80 \%$ of $\mathrm{P}_{\mathrm{ult}}$ with a frequency of $1 \mathrm{~Hz}$.

\section{Results and Discussion}

Static Tests. All six reference beams failed by pure concrete crushing, as was aimed for. Moreover, VC's average ultimate load of $144 \mathrm{kN}$ agrees well with SCC's mean failure load of $143 \mathrm{kN}$, which might be attributed to the similar compressive strength of both concrete types. As regards the average experimental midspan deflection, Fig. 3 shows slightly larger values in case of SCC, with a minimal difference up to a load of $85 \mathrm{kN}$ and a deviation of $6 \%$ near the point of collapse. Despite this, the crack width progression in Fig. 4 reveals smaller crack widths for SCC, compared to VC. However, it could be observed that SCC generates slightly more cracks, which consequently yields a denser crack pattern. When considering the concrete strain evolution (Fig. 5), it is clear that the strain failure limit of $3.5 \%$ is (practically) reached for both concrete types (especially SCC). This confirms the concrete crushing failure mode. Furthermore, the strain value for SCC exceeds that in VC with approximately $15 \%$ towards the point of failure. In the uncracked state (below 10kN) the deviation is minimal. These findings correspond with those, extracted from the deflection curve in 
Fig. 3. The strain measurements in the reinforcement steel yield nearly identical, linear stress-strain curves (Fig. 6) for both $\mathrm{VC}$ and SCC, demonstrating that no plastic rebar deformation occurs during the loading process, as could be expected.
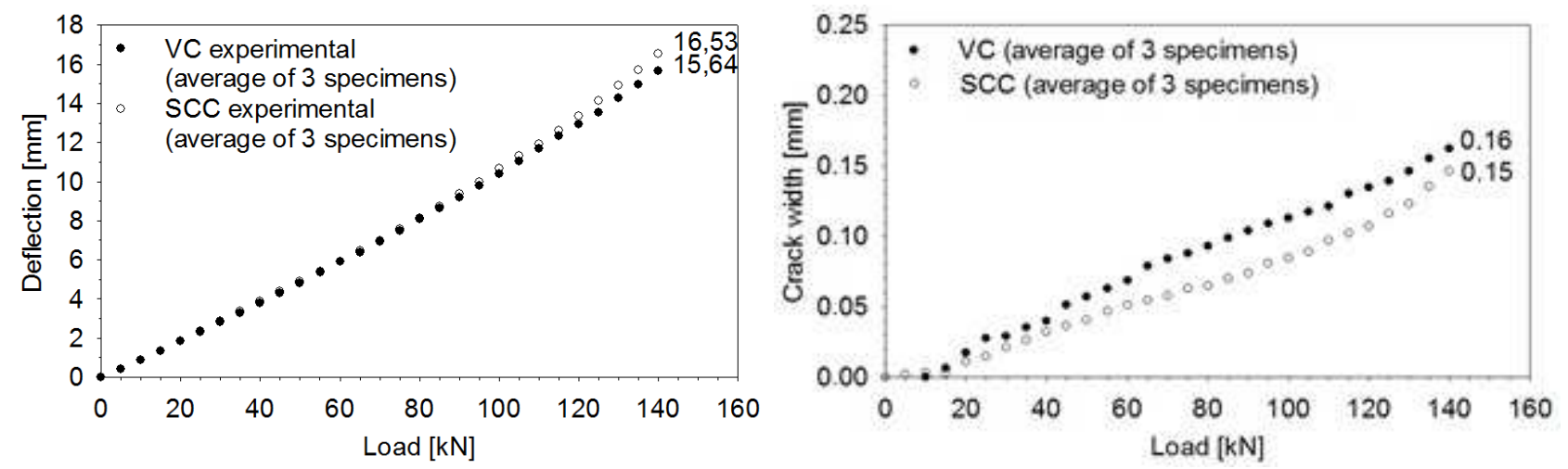

Fig. 3 - Average deflection

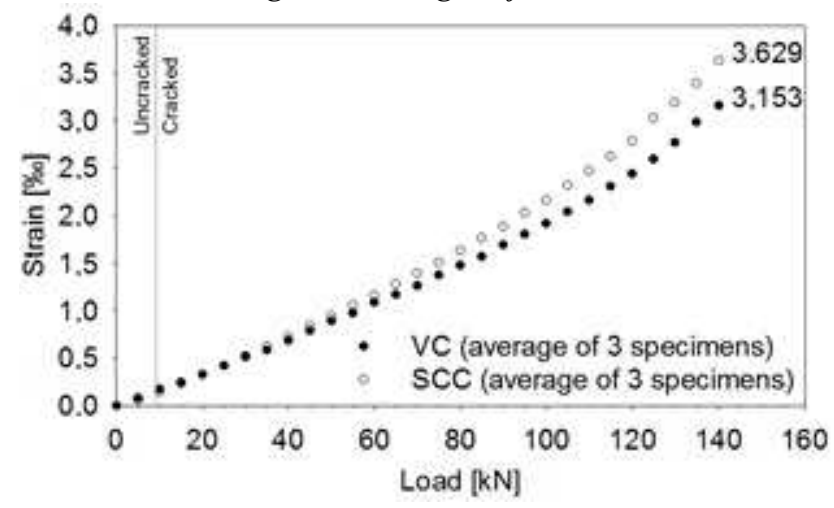

Fig. 5 - Average concrete strain

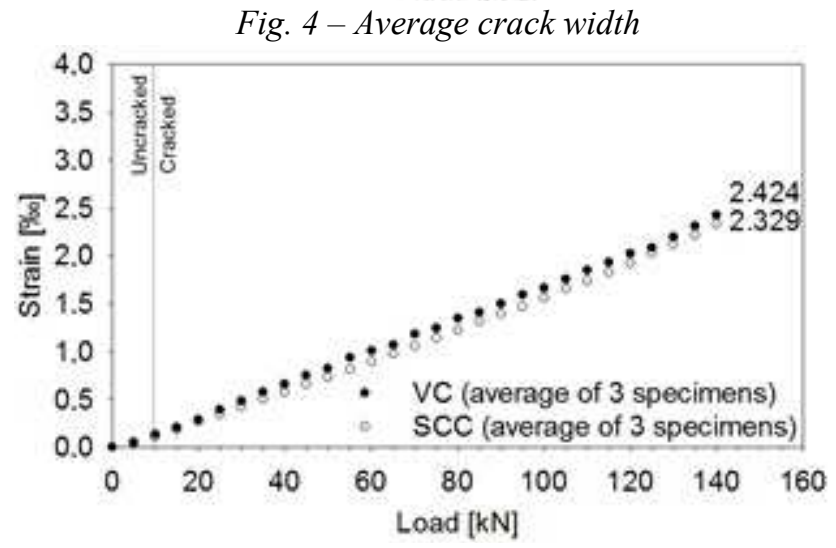

Fig. 6-Average rebar strain

Fatigue Tests. Table 3 lists the number of cycles to failure of the cyclic tests. Most of the specimens failed due to concrete crushing (CC) of the compressed zone at midspan, except for two beams (VC F1 and SCC F7), which suffered rebar fatigue (RF). Despite some scatter, it is clear that the fatigue life depends on the applied load level: the higher the upper load limit, the least cycles the beams can sustain. However, no clear differences can be noticed between VC and SCC. This is also confirmed by the experimentally determined S-N curves in Fig. 7 (where $f_{c c}$ is the ultimate static concrete crushing stress).

Table 3 -Number of cycles to failure

\begin{tabular}{|c|c|c|c|c|c|c|c|}
\hline $\mathrm{VC}$ & Load level & \# cycles & Failure mode & VC & Load level & \# cycles & Failure mode \\
\hline VC F1 & $25-65 \% \mathrm{P}_{\text {ult }}$ & 404,966 & RF & SCC F1 & $25-65 \% \mathrm{P}_{\text {ult }}$ & 360,000 & $\mathrm{CC}$ \\
\hline VC F2 & $25-65 \% \mathrm{P}_{\text {ult }}$ & 347,777 & $\mathrm{CC}$ & SCC F2 & $25-65 \% \mathrm{P}_{\mathrm{tlt}}$ & 2,136 & bad compaction \\
\hline VC F3 & $25-65 \% \mathrm{P}_{\mathrm{ult}}$ & 400,000 & $\mathrm{CC}$ & SCC F3 & $25-65 \% \mathrm{P}_{\text {ult }}$ & 88,523 & $\mathrm{LD}^{*}$ \\
\hline VC F4 & $10-80 \% \mathrm{P}_{\mathrm{ult}}$ & 2,914 & $\mathrm{CC}$ & SCC F4 & $25-65 \% \mathrm{P}_{\text {ult }}$ & 320,000 & $\mathrm{CC}$ \\
\hline VC F5 & $10-80 \% \mathrm{P}_{\mathrm{ult}}$ & 500 & $\mathrm{CC}$ & SCC F5 & $10-80 \% \mathrm{P}_{\text {ult }}$ & 11,842 & $\mathrm{CC}$ \\
\hline VC F6 & $10-70 \% \mathrm{P}_{\text {ult }}$ & 275,504 & $\mathrm{CC}$ & SCC F6 & $10-80 \% \mathrm{P}_{\text {ult }}$ & 20 & $\mathrm{CC}$ \\
\hline VC F7 & $10-70 \% \mathrm{P}_{\text {ult }}$ & 55,968 & $\mathrm{CC}$ & SCC F7 & $10-70 \% \mathrm{P}_{\mathrm{ult}}$ & 550,569 & $\mathrm{RF}$ \\
\hline
\end{tabular}

When considering the deformation evolution during the fatigue experiments, similar curves are found for the vertical displacement (Fig. 8) and strain measurements (Fig. 9). First, a long period of slightly increasing deformation is present, followed by a rapid growth up to failure. Again, the loading range is crucial: the initial (and ultimate) value increases as the upper load limit increases. Comparison of VC and SCC, however, yields conflicting results. SCC overall shows a faster concrete strain increase, but only in case of the highest load level (10-80\%) the deflection of SCC is consistently larger than that of VC. 


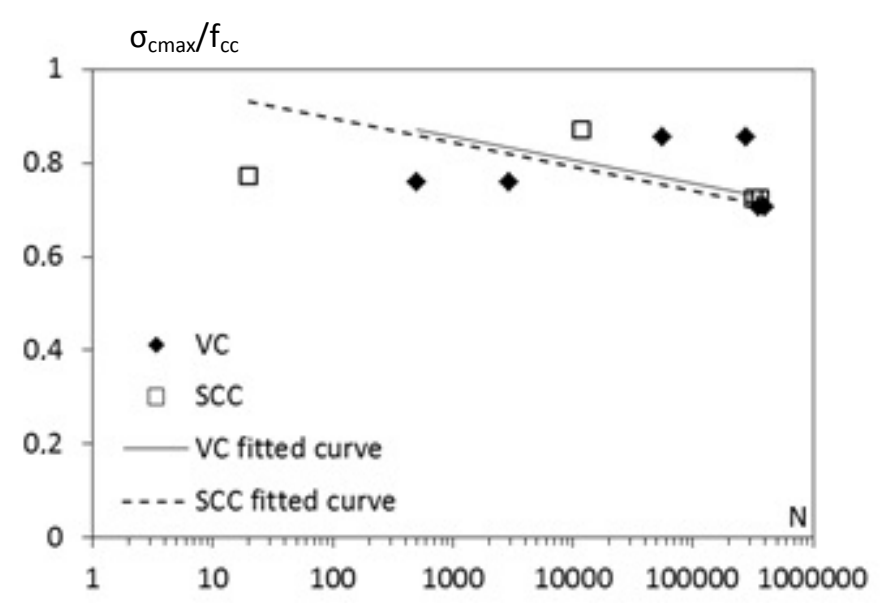

The crack width progression, which also evolves in a gradual increase and a final, short period of rapid growth, is rather stable for VC, while the crack widths in SCC grow faster. Moreover, SCC again produces more cracks, compared to VC. This might be explained by the better bond properties of SCC and the altered development of tensile stresses between the cracks.

Fig. 7 - Experimental $S$-N curve
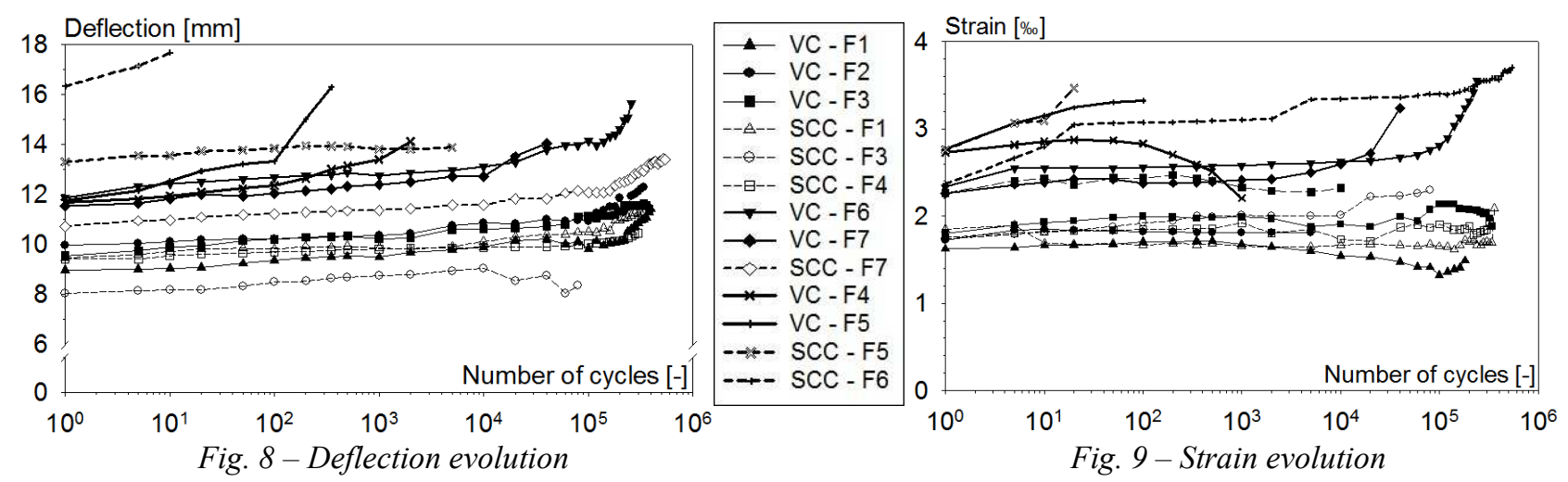

\section{Conclusions}

For most tested beams (both statically and cyclically loaded) compressive failure occured. The static ultimate load is similar for VC and SCC and yet the deflection and strain is slightly larger in case of SCC. Regarding the fatigue tests, only the highest load level (10-80\%) yields larger deformations for SCC. Also the fatigue life strongly depends on the applied lower and upper stress limits. No consistent relationship, covering the full loading scope, can be found between VC and SCC. When comparing the cracking behaviour of both concrete types, SCC generates, on average, a larger amount of cracks, which are smaller in the static experiments. During the cyclic tests, the fatigue crack propagation in SCC takes place at a more accelerated level.

\section{References}

[1] G. De Schutter et al.: Self-compacting concrete (Whittles Publishing, Caithness 2008).

[2] P.L. Domone: A review of the hardened mechanical properties of self-compacting concrete, Cement \& Concrete Composites Vol. 29 (2007), pp. 1-12.

[3] P.L. Domone: Self-compacting concrete: An analysis of 11 years of case studies, Cement \& Concrete Composites Vol. 28 (2006), pp. 197-208.

[4] J.L.A. de Oliveira e Sousa, T.N. Bittencourt: Experimental analysis of fracture processes in concrete, Journal of the Brazilian Society of Mechanical Sciences Vol. 23 No. 4 (2001).

[5] M.A. Issa, A.M. Hammad, A. Chudnovsky: Correlation between crack tortuosity and fracture toughness in cementitious material, International Journal of Fracture Vol. 60 (1993), pp. 97-105.

[6] S. Korte, V. Boel, W. De Corte, G. De Schutter: Static and fatigue fracture mechanics properties of self-compacting concrete using three-point bending tests and wedge-splitting tests, Construction and Building Materials Vol. 57 (2014), pp. 1-8. 